\title{
Finite element simulation and measurement of welding residual stresses
}

\author{
Lars Wikander†, Lennart Karlsson†, Mats Näsström† and Peter Webster \\ $\dagger$ Department of Mechanical Engineering, Luleå University of Technology, S-971 87 Luleå, \\ Sweden \\ $\ddagger$ Department of Civil Engineering, University of Salford, Salford M5 4WT, UK
}

Received 23 February 1993, accepted for publication 3 January 1994

\begin{abstract}
Residual strains and stresses in a hollow steel beam that had been welded to a D-shaped cross-section have been simulated by plane deformation finite element models and compared with experimental measurements obtained using the neutron diffraction strainscanning technique. Neutron strain scanning, in contrast to other experimental techniques, is capable of measuring, accurately, non-destructively and in detail, the internal strain state at selected locations and directions within a component. This makes it a preferred method for validating model calculations of strain and stress distributions in components. In the finite element simulations a plane deformation model incorporating temperature-dependent material properties was adopted. With the assumptions for material properties that were made, the plane deformation model predicts the overall bending of the beam and the overall residual strains and stresses reasonably well. Locally, in the weld metal the predicted residual strains and stresses depend very much on the values of the thermal strain, which in one simulation include volume changes due to solid-state phase transformations. In the other simulation presented here the volume changes due to solid-state phase transformations were not accounted for.
\end{abstract}

\section{Introduction}

If components are to be welded it is important to know what the residual deformation and residual stresses will be. The distortions must be known, or better still avoided, if welded components are mounted together to form a structure. The only way in the design stage to predict these deformations and stresses is to use a theoretical model for the simulation of the welding process. The most suitable model to use is the finite element method (FEM). The results from such simulations, even from a simplified model, could be incorporated in a knowledge-based system for the design of welded structures. In general, it is best to adopt a fully three-dimensional model, but such models are usually very costly and time consuming so simplified models have to be used for welding problems. Fully threedimensional simulations of welding are very recent [1], as is also the case for the simulation of welding of shell structures [2]. To decrease the size of the problem a combined solid and shell modelling of welding was performed in [3] and re-zoning and sub-structuring techniques were used in three-dimensional modelling of welding in [4]. These threedimensional models of welding are needed in many cases for accurate simulations. However, the computing time is shortened substantially by use of adequate two-dimensional models, which therefore are of great importance in many practical situations. To ensure that the simulations perform reliably it is necessary to use a model that has been verified with data obtained by a suitable experimental method. 


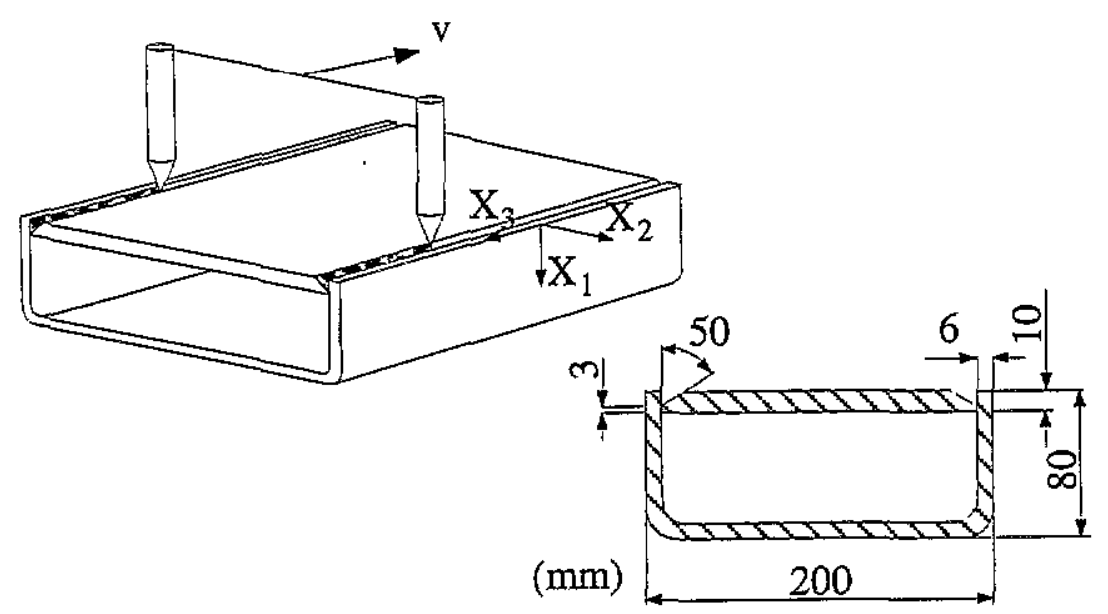

Figure 1. The welded beam to be analysed.

The main purpose of this paper is to experimentally test, using neutron strain scanning data, the plane deformation modelling of the welding of a hollow beam with D-shaped crosssection, as shown in figure 1. The plane deformation model in [5] was compared with a plane strain model and a generalized plane strain model. In plane strain one assumes that the out-of-plane strain $\epsilon_{33}$ is equal to zero, as well as the shear strains $\epsilon_{13}$ and $\epsilon_{23}$. Generalized plane strain and plane deformation differ from plane strain in that in generalized plane strain the out-of-plane strain $\epsilon_{33}$ is assumed to be a constant for the analysed cross-section, and in plane deformation the out-of-plane strain $\epsilon_{33}$ is allowed to vary linearly over the cross-section according to the equation $\epsilon_{33}=\beta_{1}+\beta_{2} x_{1}+\beta_{3} x_{2}$. In other words, in the plane deformation model the beam cross-section is allowed to translate in the longitudinal $\left(x_{3}-\right)$ direction of the beam and to tilt around the $x_{2}$-direction. Due to symmetry the tilting around the $x_{1}$-direction is zero (figure 1 ). The simulation of the manufacturing process was divided into two parts: bending analysis and a thermomechanical analysis of the welding (see below). The thermomechanical analysis comprises a thermal analysis and a mechanical analysis where the mechanical analysis is performed immediately after the thermal analysis in each time step.

\section{Manufacturing procedure and welding configuration}

The welded component was constructed from a $10 \mathrm{~mm}$ thick structural steel plate, Swedish type SS142132, and from $6 \mathrm{~mm}$ plate type SS142172 that was bent and welded to the $10 \mathrm{~mm}$ plate to form the shape shown in figure 1. The cross-sectional area of the plate was $10 \times 188 \mathrm{~mm}^{2}$ and the length was $200 \mathrm{~mm}$. The filler material was ESAB OK 1251 . During the welding a fixture kept the U-beam and the plate in position. This fixture acted with a constant force of $150 \mathrm{kN} \mathrm{m}^{-1}$ on the parallel walls of the U-beam. The weIding arcs shown in figure 1 moved simultaneously in the $x_{3}$-direction with a constant velocity $v=0.067 \mathrm{~m} \mathrm{~s}^{-1}$. The gross heat input $Q$ was $0.993 \mathrm{MJ} \mathrm{m}^{-1}$ and the arc efficiency $\eta$ was estimated to be 0.80 . The weld geometry is shown in figure 1 . It should be noted that the stresses caused by the welding process introduced some distortions in the component. In the $6 \mathrm{~mm}$ plate there was a noticeable curvature in the 'straight' sections adjacent to the 
bends and the $10 \mathrm{~mm}$ plate was twisted such that it was not quite planar. The difference between the actual component and the drawings was in some places about $1 \mathrm{~mm}$.

\section{Experimental measurements of residual stresses}

The methods available for the measurement of residual stresses in components may be categorized under two headings-mechanical and physical.

The mechanical methods involve the removal of part of the component, by cutting or drilling, as in the sectioning, slotting, hole-drilling and Sachs boring techniques [6-9]. The residual stresses are then calculated from the changes in strain that are observed as the stressed components relax as material is removed. These techniques are all destructive or semi-destructive and change the stress state of the component.

Physical methods involving acoustic, magnetic and diffraction techniques have all been used for non-destructive measurements of residual stresses in components, and each have their advantages and limitations. The acoustic method is a rapid and portable technique but interpretation is affected by texture and preferred orientation in the sample [10]. The magnetic, Barkhausen, method is also rapid and portable, and semi-quantitative, but is limited to near-surface measurements on ferromagnetic, usually steel, components [11]. The $\mathrm{x}$-ray-diffraction method is now well established and may be used for on-site measurements [12]. In this technique strain is determined directly from measurements of atomic lattice spacings. The technique is essentially limited, however, to surface measurements as $\mathrm{x}$-rays are strongly absorbed by most engineering materials. The neutron diffraction method is a relatively new technique which, in principle, is similar to the $\mathrm{x}$-ray method $[13,14]$. It differs in that neutrons usually penetrate several centimetres into most engineering materials and hence may be used for the non-destructive measurement of internal as well as surface stresses. However, the technique is only available at laboratories with high-flux nuclear reactors or accelerator-induced neutron sources.

In this investigation it was necessary to obtain non-destructive experimental measurements of the residual stresses at a number of locations, and in several directions, near the surface, and in the interior, of a welded steel beam with D-shaped cross-section in order to verify a finite element model of welding. Of the physical techniques available only the neutron diffraction method was feasible. The neutron technique, as used, is described below.

\subsection{The neutron diffraction method}

With the neutron diffraction method, as with the x-ray method, components of strain are determined directly from measurements of changes in the lattice spacings of crystals. Stresses are then calculated from these strains [14].

When a monoenergetic beam of neutrons, of wavelength $\lambda$, is incident upon a polycrystalline sample Bragg scattering occurs and a diffraction pattern with sharp maxima at specific angles is produced. The angular positions of the Bragg reflections are defined by the Bragg equation

$$
2 d \sin \theta=\lambda \text {. }
$$

where $2 \theta$ is the angle of the diffracted beam relative to the incoming beam and $d$ is the spacing of atomic planes contributing to a particular Bragg reflection $(h k l)$ with normals in the direction of the scattering vector $Q$. The direction of $Q$ is parallel to the line bisecting 
the angle between the incoming and reflected neutron beams. A small change $\delta d$ in the lattice spacings of a crystalline material results in a corresponding small change $\delta \theta$ in the angular position of the Bragg reflection given by

$$
\delta \theta=(\delta d / d) \tan \theta
$$

The lattice strain $\epsilon$ in the direction $Q$, normal to the scattering planes, is thus

$$
\epsilon=\delta d / d=-\delta \theta \cot \theta
$$

The strain tensor at a point, and hence the stress state, may be obtained by determining the lattice strain as a function of sample orientation. In general, measurements in six orientations may be required but for plane stress conditions, or if the principal stress directions are known, measurements in three, often orthogonal, directions may be sufficient.

A Bragg reflection from a region of constant strain, as measured by a high-resolution neutron diffractometer, usually has a Gaussian intensity profile, the centre of which may be determined accurately by a peak-fitting routine. In a simple system an elastic change in strain causes only a small shift in peak position. In a more complex system peak broadening can occur as a result of plastic deformation, and non-Gaussian peak shapes can result if a significant strain gradient is present in the sampled volume. The technique integrates all the scattering from the volume sampled and, consequently, if there is a significant parameter variation within that volume it has a corresponding effect on peak shape, width and height as well as position. This integration enables a substantial amount of additional information to be obtained about the physical state of the sample but complicates the analysis.

The sensitivity and resolution of the neutron diffraction method depend upon the crystallite size distribution, the angular resolution of the system and the number of neutrons counted in a Bragg peak. The number of crystallites in the sampled volume should be large enough to produce a good statistical average of crystallite orientation. The neutron count is proportional to the volume sampled and the counting time and should be large enough to provide an adequate statistical value. The count is also affected by preferential orientation of crystalline planes and by absorption in the sample. The size and shape of the sampling volume should be chosen so as to maximize neutron counts without causing significant peak distortion.

\subsection{Experimental details}

The experiments were carried out at the Institut Laue Langevin, Grenoble, using the D1A high-resolution diffractometer. The diffractometer was modified, to make strain measurements, by using the Salford/Imperial 'Engineering Package'. Data analysis was carried out using the 'SALFIT' software package.

The diffractometer is shown diagrammatically in plan view in figure 2. Thermalized neutrons are guided from the high-flux-beam reactor to the monochromating crystal, where an essentially monoenergetic beam is reflected through a reference point at a height of $500 \mathrm{~mm}$ above the centre, and on the axis of rotation, of the diffractometer table. The position and cross-section of the beam are defined by a precisely made adjustable inlet mask.

The angle of the diffracted beam is defined by 'Soller slits' in front of the detector and the volume sampled is defined by an exit mask in the detected beam. For optimum spatial resolution the angle between the incoming and detected beams is usually chosen to be close to $90^{\circ}$. A typical sampling volume would be a cube of side $2 \mathrm{~mm}$. A diffraction pattern 


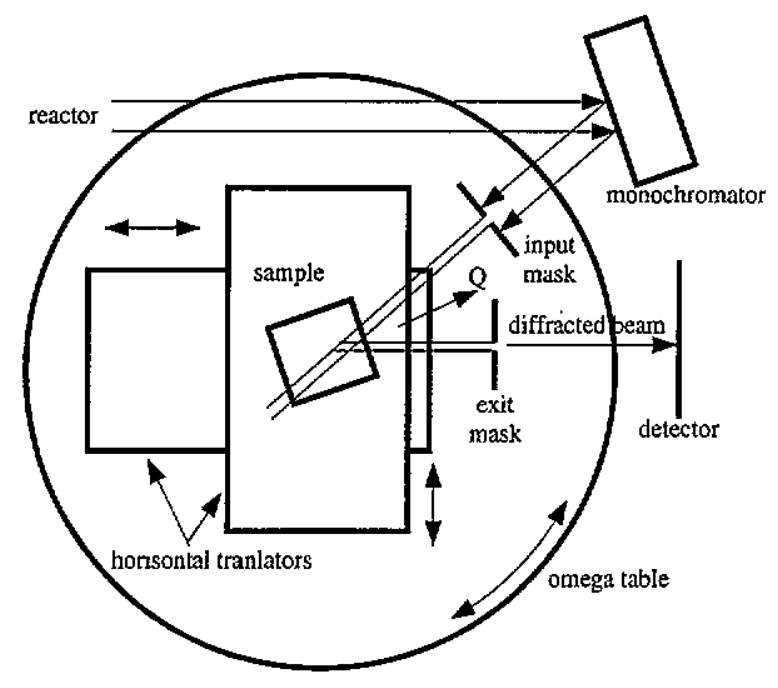

Figure 2. Diffractometer used in the measurements.

is obtained by moving the neutron detector in small angular steps about the position of the Bragg peak. The angular resolution is such that it is possible to determine peak shifts to about five thousandths of a degree, which usually corresponds to about 50 microstrain.

The component is positioned relative to the reference point using three orthogonal, computer-controlled, translators in conjunction with a theodolite. Sample positioning to better than $0.1 \mathrm{~mm}$ is achievable relative to the reference point. Strain measurements are made at different points in a component by translating it in incremental steps through the sampling volume. Rotation of the component enables strains to be measured in different directions.

\subsection{Experimental procedure}

To determine the residual strains measurements were made of angular shifts in the position of the (211) Bragg reflection using a neutron wavelength of $0.19 \mathrm{~nm}$. The (211) reflection has a Young's modulus close to that measured by conventional techniques for the bulk of an isotropic BCC material and, at a wavelength of $0.19 \mathrm{~nm}$, the reflection occurs for $2 \theta$ at approximately $109^{\circ}$ which is close to the optimum $90^{\circ}$ for best spatial resolution and is also large enough to give sufficient angular dispersion. Measurements were made at points $\left(x_{1}, x_{2}, x_{3}\right)$ in the directions $x_{1}, x_{2}$ and $x_{3}$ in a series of scans by translating the component through the sampling volume and by rotating it about axes through the centre of the diffractometer. The co-ordinate system used is indicated in figure 1. Initially measurements were made on four annealed samples and four 'super-annealed' samples, which had been subjected to an extra anneal, from the $10 \mathrm{~mm}$ and $6 \mathrm{~mm}$ plates of types 142132 and 142172 steel, as used for the welded component, to determine the 'stress-free' zero angle to enable subsequent measured peak positions to be converted to strains. The results averaged $109.53^{\circ}$.

The experiments on the D-shaped component were designed to measure the strains in the $x_{1}, x_{2}$ and $x_{3}$ orientations at a series of points $\left(x_{1}, x_{2}, 20\right)$ as indicated in figure 3 . The value $x_{3}=0$ corresponds to an $x_{1}-x_{2}$ plane through the midpoint of the length of the weld approximately $100 \mathrm{~mm}$ from each end. The measurements were made at these points, instead of $\left(x_{1}, x_{2}, 0\right)$, to avoid neutron-beam absorption and peak-distortion problems that would 
have occurred in some orientations as the diffracted beam would have passed partly through and partly past parts of the component not being measured. The $20 \mathrm{~mm}$ displacement obviated the problem, and permitted reduced counting times as no part of the diffracted beam then passed through the edge of the $6 \mathrm{~mm}$ plate when the $10 \mathrm{~mm}$ plate was being measured or vice versa. An elongated sampling volume of $2 \times 2 \times 10 \mathrm{~mm}^{3}$ was used for $x_{1}$ and $x_{2}$ measurements when the $x_{3}$ direction was vertical, to enhance counting statistics. For all other measurements an approximately cubic sampling volume of $2 \times 2 \times 2 \mathrm{~mm}^{3}$ was employed.

In principle sample positioning to better than $0.1 \mathrm{~mm}$ is possible relative to the reference point. However, precise positioning was limited by the difficulties of defining a reference point on the component. The maximum error in positioning is estimated to be $1 \mathrm{~mm}$.

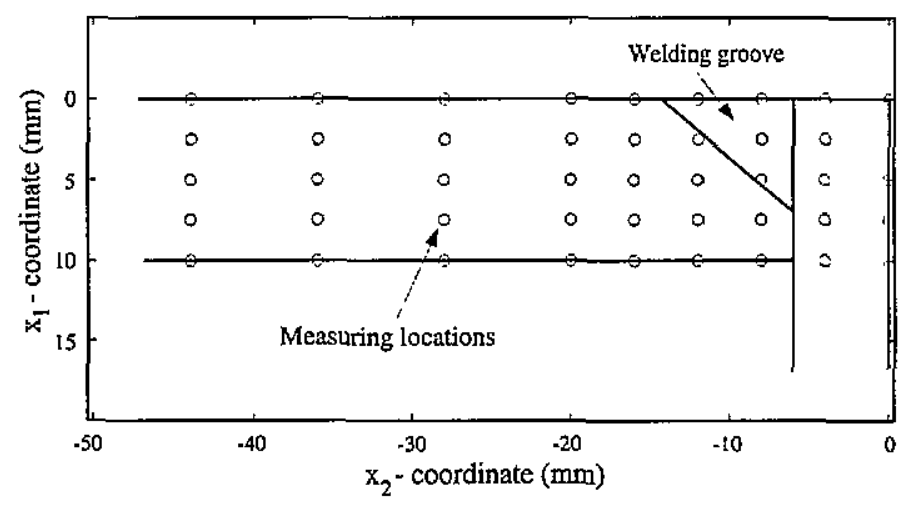

Figure 3. Measuring locations for neutron diffraction measurements.

\section{Finite element simulations}

To take into account the two different manufacturing processes involved in the manufacturing of the D-profile beam, the FE analysis was separated in two parts. Firstly, the cold bending of a flat plate to a U-profile beam was analysed (see subsection 4.1 below), assuming a plane state of strain. Secondly, the welding of the flat plate to the U-shaped beam (as shown in figure 1) was simulated (see subsection 4.2 below) with the assumption of plane deformation. In the bending analysis the FE code NIKE2D was used. NIKE2D is an implicit, static and dynamic finite deformation, finite element code applicable to axisymmetric, plane strain and plane stress problems [15]. The residual stress field due to plastic deformation of this component was included in the subsequent welding analysis in the way that the residual stresses due to the cold bending were used as initial stress state in the simulation of the welding. In the (thermomechanical) welding analysis an in house implicit finite element code was used. One time step in this thermomechanical welding analysis comprises one or several (sub-) steps where the nodal temperatures are calculated. These nodal temperatures are then averaged in each element in order to give a constant temperature in each element. A constant temperature in each element gives a constant thermal strain, which is consistent with the linear variation of the displacements within an element. These element temperatures are used as thermal load in the subsequent mechanical analysis in each of the time (load) 
steps. In the first time step of the welding analysis the residual stress field transferred from the bending analysis had to be iterated to equilibrium under the assumption of plane deformation as plane strain was assumed in the bending analysis. An outline of the FE procedure adopted in the welding analysis using the in-house code is given in the Appendix [16].

The mechanical field is coupled to the temperature field through the thermal strain and the temperature-dependent constitutive properties. Two different welding analyses were performed. In one of these analyses volume changes due to solid-state phase transformation were accounted for; this is referred to as case A. In the other welding analysis these volume changes were neglected; this is referred to as case B. In both of these analyses a modified plane strain assumption, plane deformation, was used. Plane deformation differs from plane strain only in the nodal displacement-strain relationship. The out-of-plane strain, $\epsilon_{33}$, in this case is allowed to vary linearly in the analysed cross-section as $\epsilon_{33}=\beta_{1}+\beta_{2} x_{1}+\beta_{3} x_{2}$. The reciprocals of $\beta_{2}$ and $\beta_{3}$ represent the radii of curvature with respect to $x_{2}$ - and $x_{1}$-coordinate axes, respectively, and $\beta_{1}$ is simply the strain in the $x_{3}$-direction at the point $x_{1}=0$, $x_{2}=0$ (see figure 1). This modification increases the number of degrees of freedom in a model by at most three, if symmetry cannot be exploited. Thus, the additional computing cost for this type of analysis is insignificant.

\section{4.l. Bending analysis}

In the finite element analysis of the bending of a flat plate plane strain conditions were assumed and large deformations were accounted for. The plate was made of the material SS (Swedish steel) 142172. The cross-sectional area of the plate was $330 \times 6 \mathrm{~mm}^{2}$ and the length was $200 \mathrm{~mm}$. The plane analysed was divided into 795 elements with a twoby-two Gauss quadrature rule (see figure 4). The material was assumed to be elastoplastic with isotropic strain hardening. The material properties used are modulus of elasticity $E=210 \mathrm{GPa}$, yield stress $\sigma_{\mathrm{y}}=295 \mathrm{MPa}$, Poisson's ratio $v=0.3$ and hardening modulus $H^{\prime}=5 \mathrm{GPa}$.

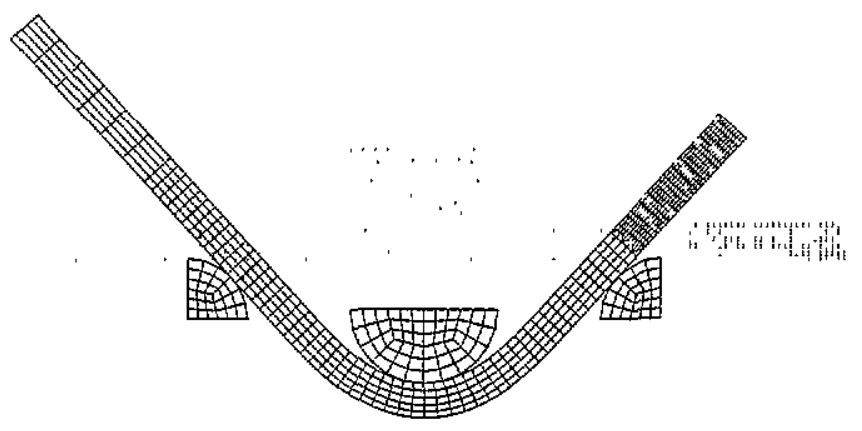

Figure 4. Finite element model used in the bending analysis.

\subsection{Welding analysis}

In the finite element simulation of the welding, half the cross-section (including the fixture) shown in figure 5 was divided into 1130 quadrilateral elements with bilinear base functions. 
The mechanical analysis was performed after the thermal analysis in each time increment. Due to symmetry only one half of the beam had to be modelled. Thermodynamic coupling was not considered, i.e. heat generated by plastic straining of the material was neglected. The mechanical system had 2574 degrees of freedom and the thermal system 1275 . The finite element mesh is shown in figure 5.

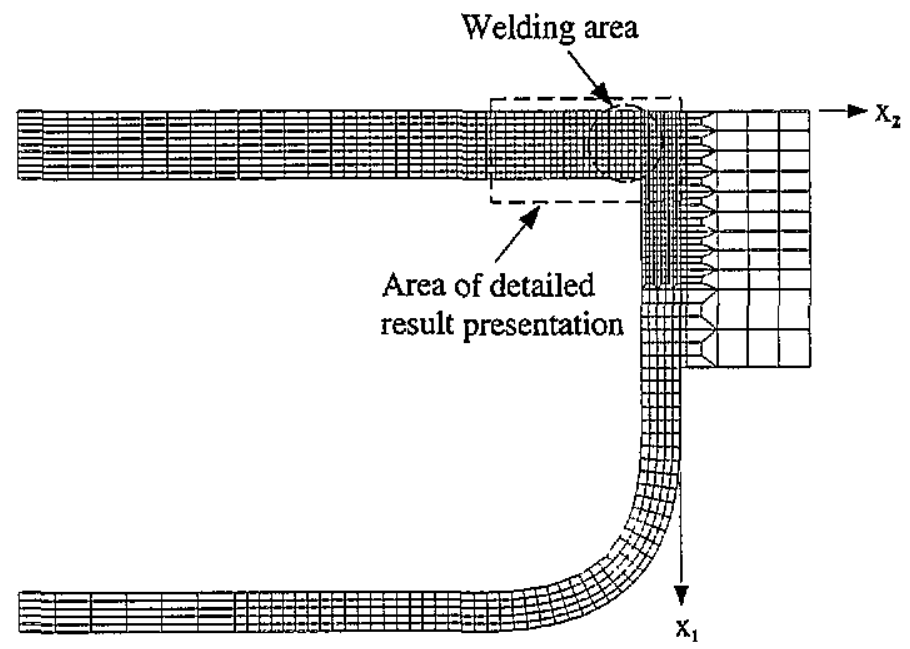

Figure 5. Finite element mesh used in the welding analysis.

The thermal loading consisted of nodal heat input applied in the welding groove. The heat input was linearly increased from zero at $t=0 \mathrm{~s}$ to a constant magnitude in the interval $[0.5 \mathrm{~s}, 2.5 \mathrm{~s}]$ and then linearly decreased to zero at $t=3 \mathrm{~s}$. This means that the heat is deposited simultaneously along the whole length of the weld, which implies that the welding velocity is assumed to be infinite. The error introduced into the temperature analysis by assuming infinite welding speed is negligible except for a small area in the vicinity of the heat source [17-19]. The fixture will act as a heat sink and influence the temperature field considerably, and must therefore be included in the thermal analysis. The temperaturedependent thermal material properties (heat capacity and thermal conductivity) are shown in figure 6. The same thermal properties were assumed for both materials SS 142172 and SS 142132 , as well as the fixture. The high value of the heat capacity $c$ between $1480^{\circ} \mathrm{C}$ and $1530^{\circ} \mathrm{C}$ (see figure 6), corresponds to a latent heat $M$ of $260 \mathrm{~kJ} \mathrm{~kg}^{-1}$. The heat transfer coefficient between the beam and the fixture was assumed to be $300 \mathrm{~W} \mathrm{~m}^{-2}{ }^{\circ} \mathrm{C}^{-1}$. The convective surface heat transfer coefficient between steel and air was $12 \mathrm{~W} \mathrm{~m}^{-2}{ }^{\circ} \mathrm{C}^{-1}$.

The thermal dilatation $\epsilon^{\mathrm{t}}$ is shown in figure 7 and the temperature-dependent mechanical material properties are shown in figures 8 and 9 . The curves in figure 7 , which were experimentally obtained in [20], indicate at which temperatures the solid-state phase transformations occur. During heating the top curve in the dilatation diagram was followed and, depending on the maximum temperature reached, different curves were followed during cooling. Figure 8 should be interpreted in a similar manner: during heating the yield stress, $\sigma_{y}$, varies according to the lines marked 'heating' and depending on peak temperature the yield stress follows a certain line during cooling. 


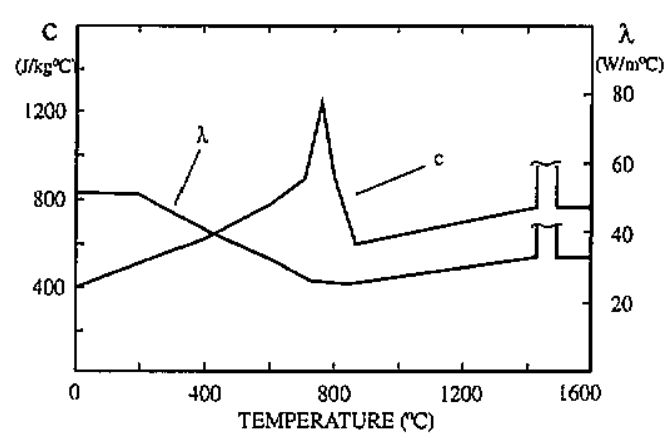

Figure 6. The heat capacity $c$ and thermal conductivity $\lambda$.

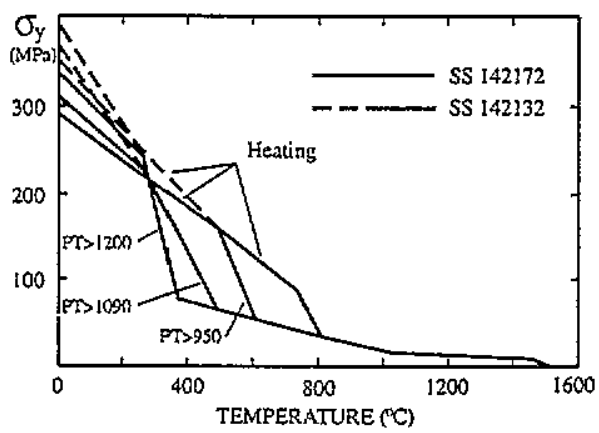

Figure 8. The yield stress.

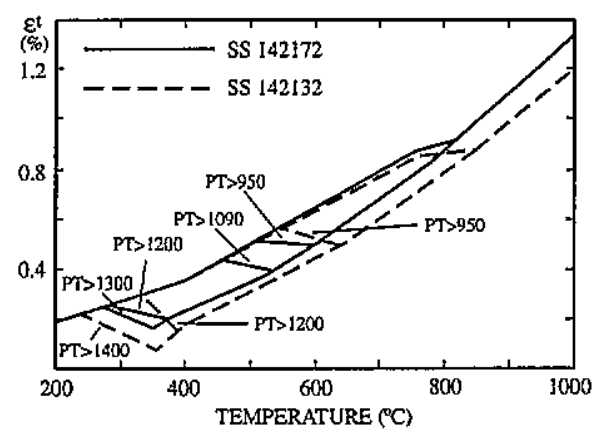

Figure 7. The thermal dilatation.

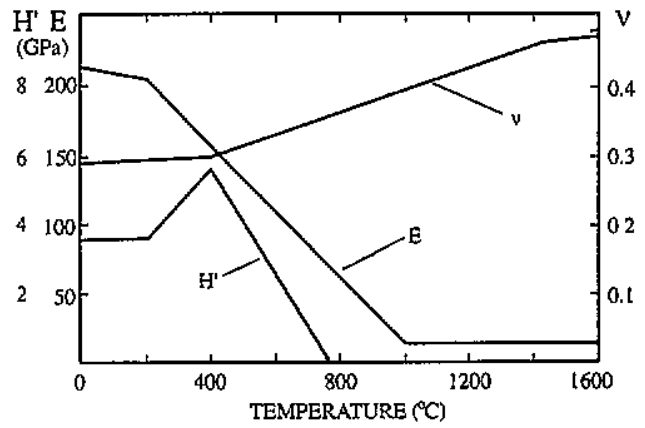

Figure 9. The elastic modulus $E$, Poisson's ratio $\nu$ and the hardening modulus $H^{\prime}$.

For peak temperatures other than those indicated in figures 7 and 8 the values of $\sigma_{y}$ and $\epsilon^{t}$ were linearly interpolated. In the analysis where no volume changes due to solid state phase transformation were accounted for the top curve of the thermal dilatation $\epsilon^{t}$ was followed during heating as well as cooling (see figure 7). The yield stress $\sigma_{y}$ in this case varies during both heating and cooling according to the curves marked 'heating' (see figure 8). The following parameters were also needed in the mechanical analysis: Young's modulus $E$, Poisson's ratio $v$ and the hardening modulus $H^{\prime}$. The temperature dependence of $E, v$ and $H^{\prime}$ are shown in figure 9. The pressure due to the fixture was applied on the beam walls for $30 \mathrm{~s}$. To exclude other influences of the fixture on the mechanical analysis the Young's modulus of the fixture was assigned a very low value. All the above-mentioned material properties were taken from [19].

\section{Results}

Figures $10(\mathrm{~A}), 11(\mathrm{~A}), 13,14,15(\mathrm{~A}), 16(\mathrm{~A})$ and $17(\mathrm{~A})$ show results from the simulation where volume changes due to solid-state phase transformation were accounted for (case $A$ ), whereas figures $10(\mathrm{~B}), 11(\mathrm{~B}), 15(\mathrm{~B}), 16(\mathrm{~B})$ and $17(\mathrm{~B})$ show results from the simulation 

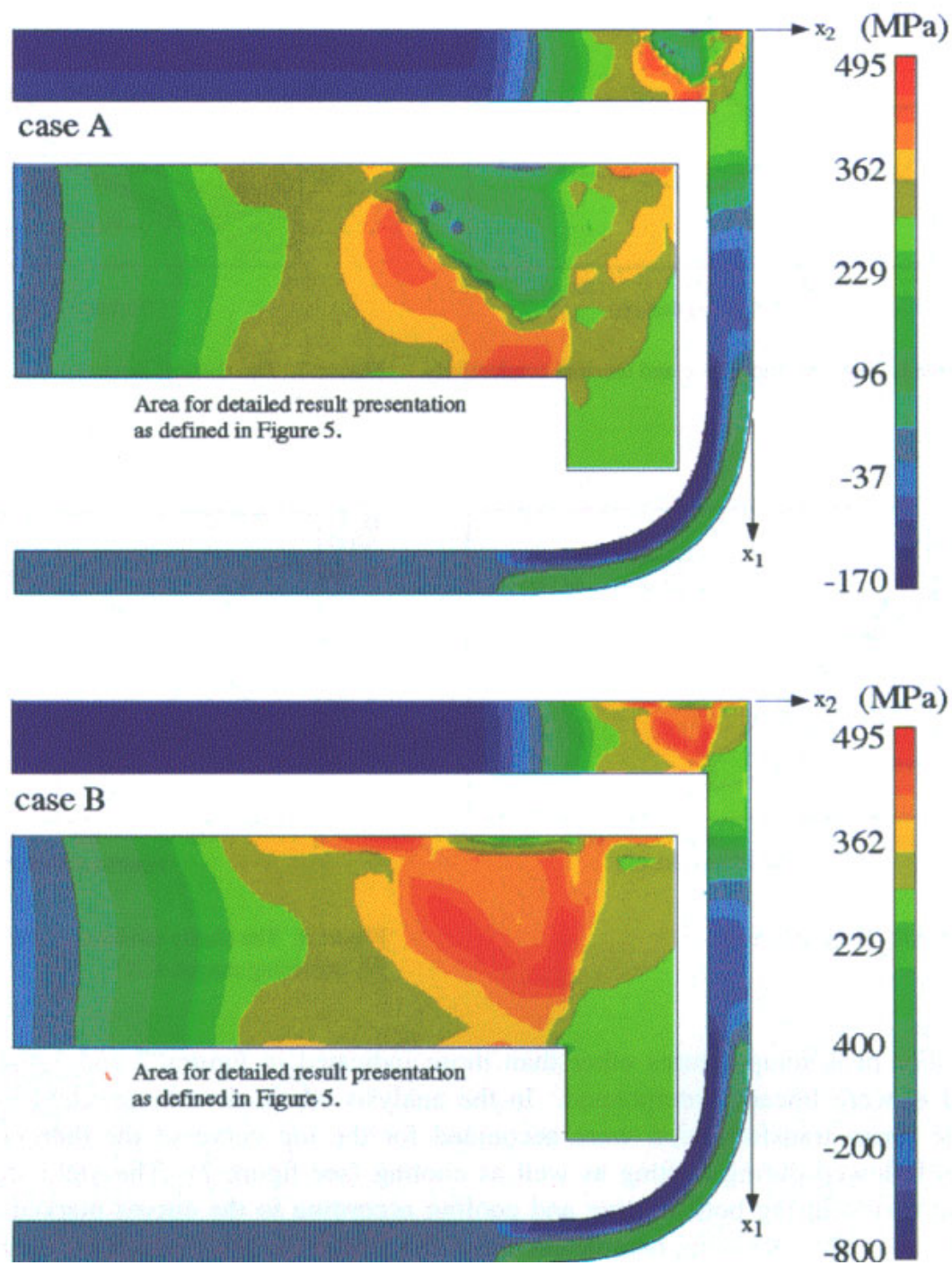

Figure 10. (A) Contours of calculated residual longituditual strest, or3. Wolume chinges die to phase traniformations are accounted for. (B) Contburs of calculated residual longitudinal streass, \%33. Volime changes due to phinge transformincioas are not accountod for.

where volume changes were neglected (case B). Figures 10-14 display contours of the residual stresses and strains. The area of detailed result presentation as defined in figure 5 has been enlarged in each of the figures 10,11,13 and 14. The measured and calculated residual strains for the section shown in figure 3 are presented in diagram form in figures 1517. These diagrams malke a detailed comperison of measured and calculated rosidual strains possible

The calculated rotation of the cross-section corresponds to a radius of curvature $\left(1 / \beta_{2}\right)$ 

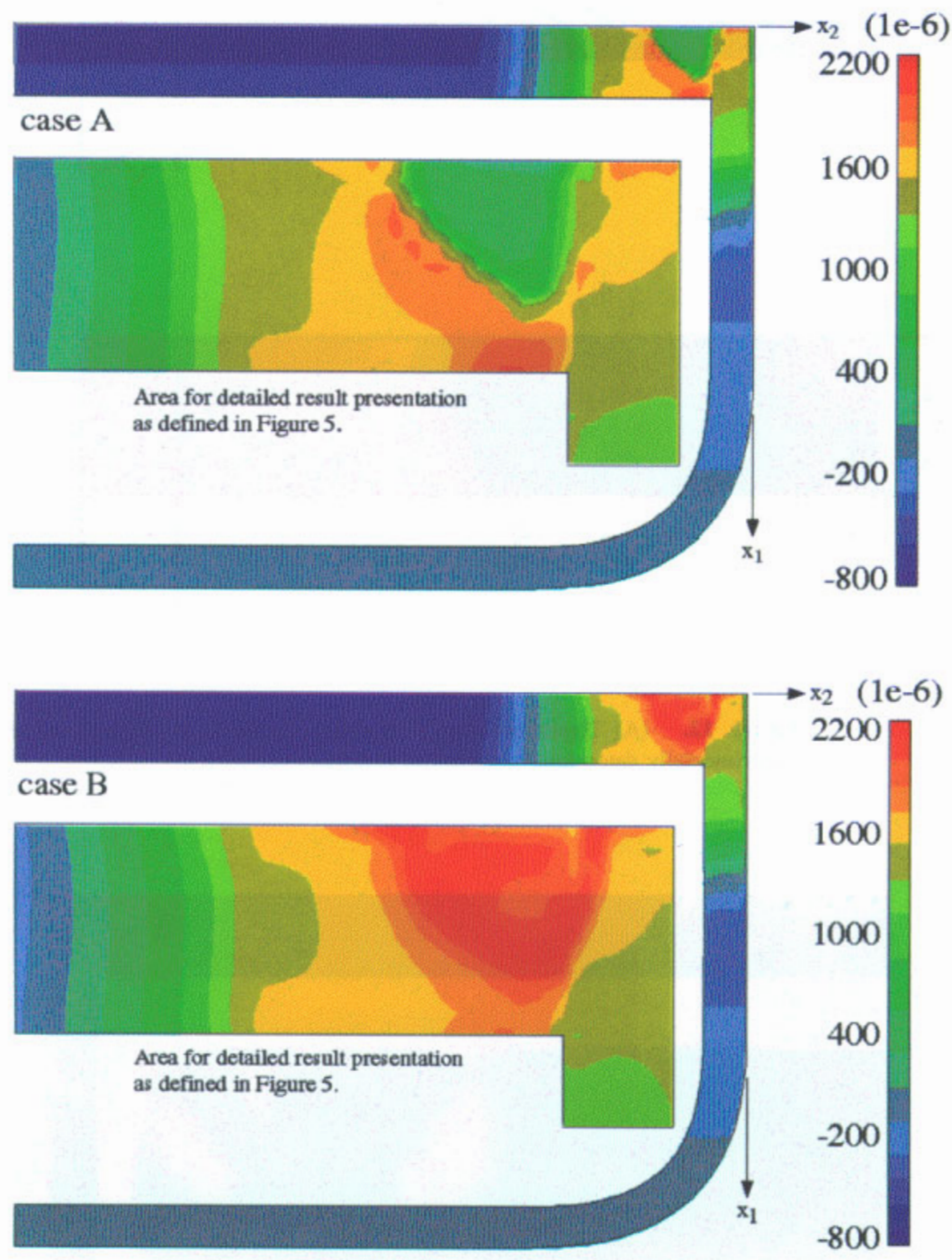

Fgare 11. (A) Contours of calculated rasidual longitudinal strain, 635 . Volume changes due to phase transformutions are accounted for. (B) Contours of calculated residual longitudinal strain, E33. Vohume changes due to phase transformations are not accounted for.

\section{of $119.5 \mathrm{~m}$.}

The calculated out-of-plane residual stress, $\sigma_{33}$, is shown in figure 10. The corresponding residual strain is found in figure 11. As can be seen for case B in figures 10(B) and 11(B) the maximum residual stresses and strains occur in the region that has experienced the highest temperatures, i.e. the welding groove. This can be explained by the fact that the shrinkage of the filler material will be restrained by the surrounding material. Since the displacement in this $x_{3}$-direction (see figure 1 ) is more restricted than in the other two 

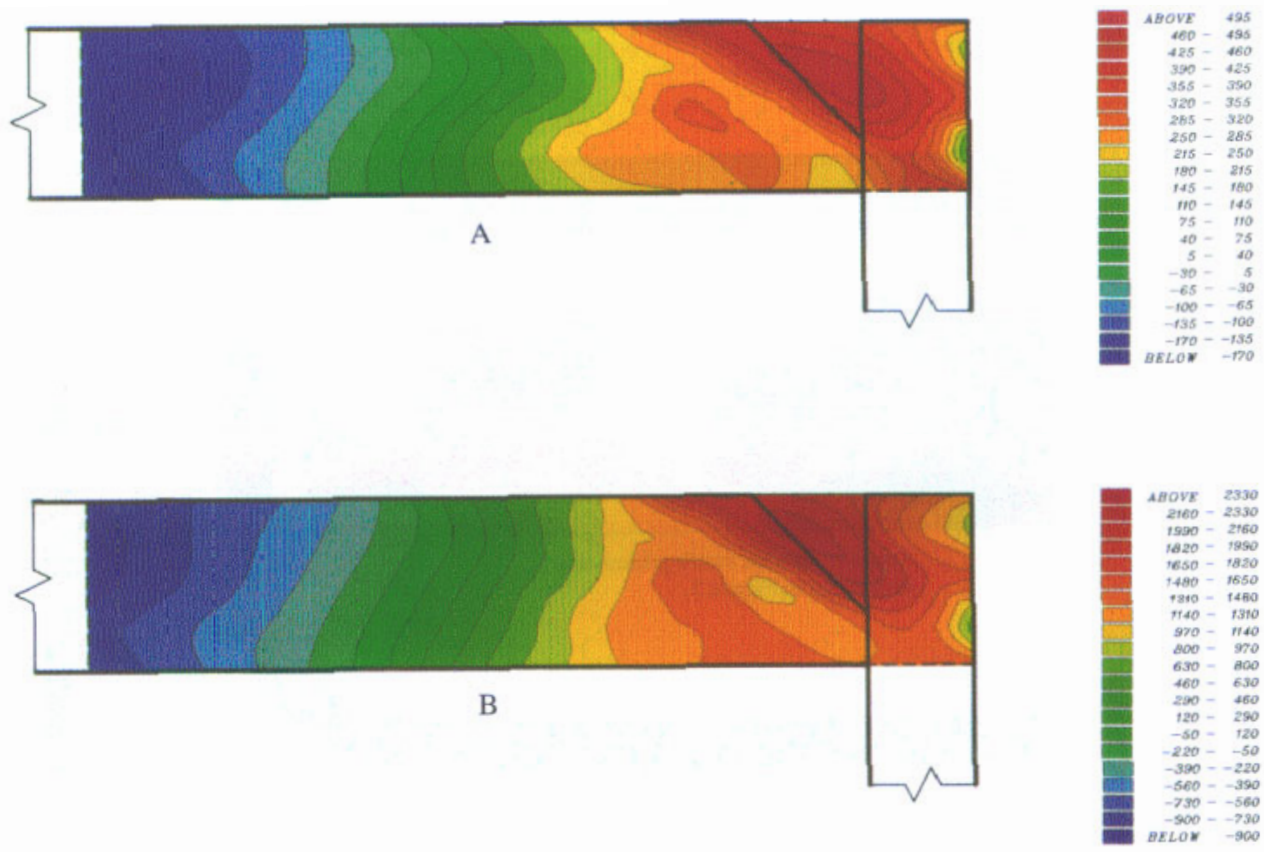

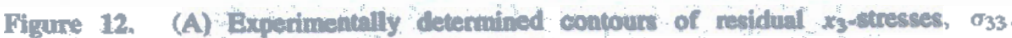
Experimentally determined contours of residual $x_{3}$-stratins, $e_{33}$.

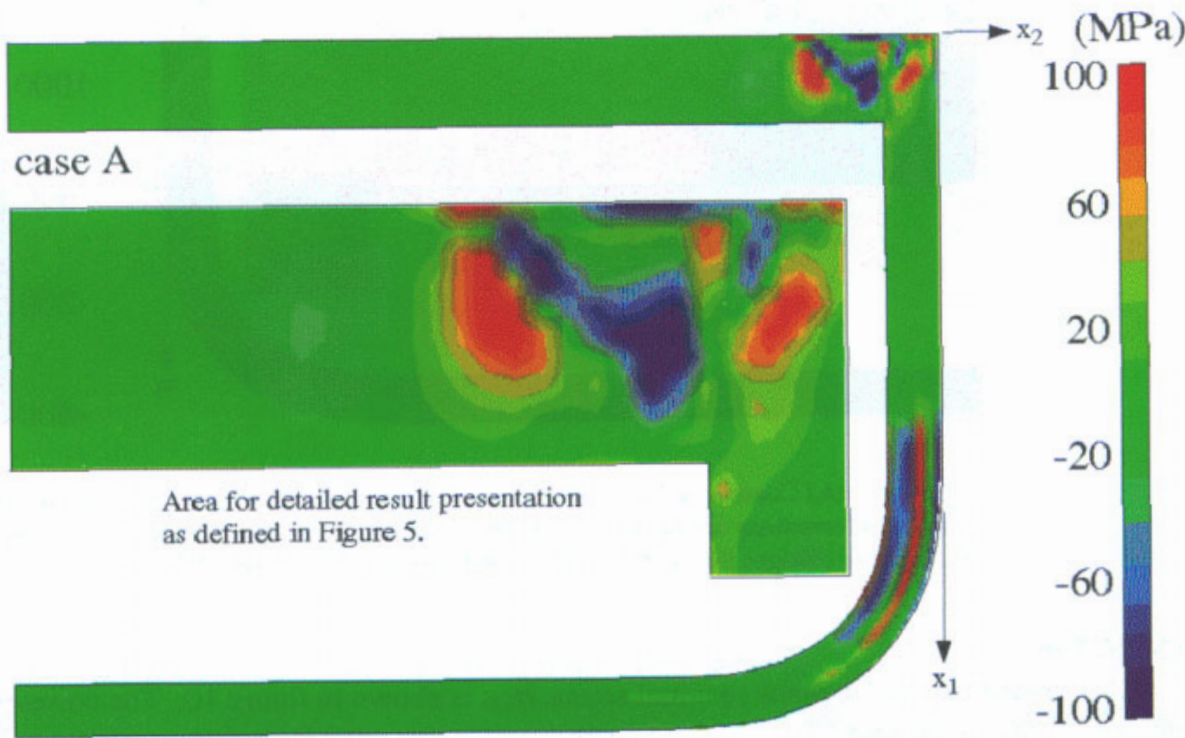

Figure 13. Contours of calculated residual $x_{1}$-stress, $\sigma_{11}$. Volume changes due to phase transformations are accounted for. 


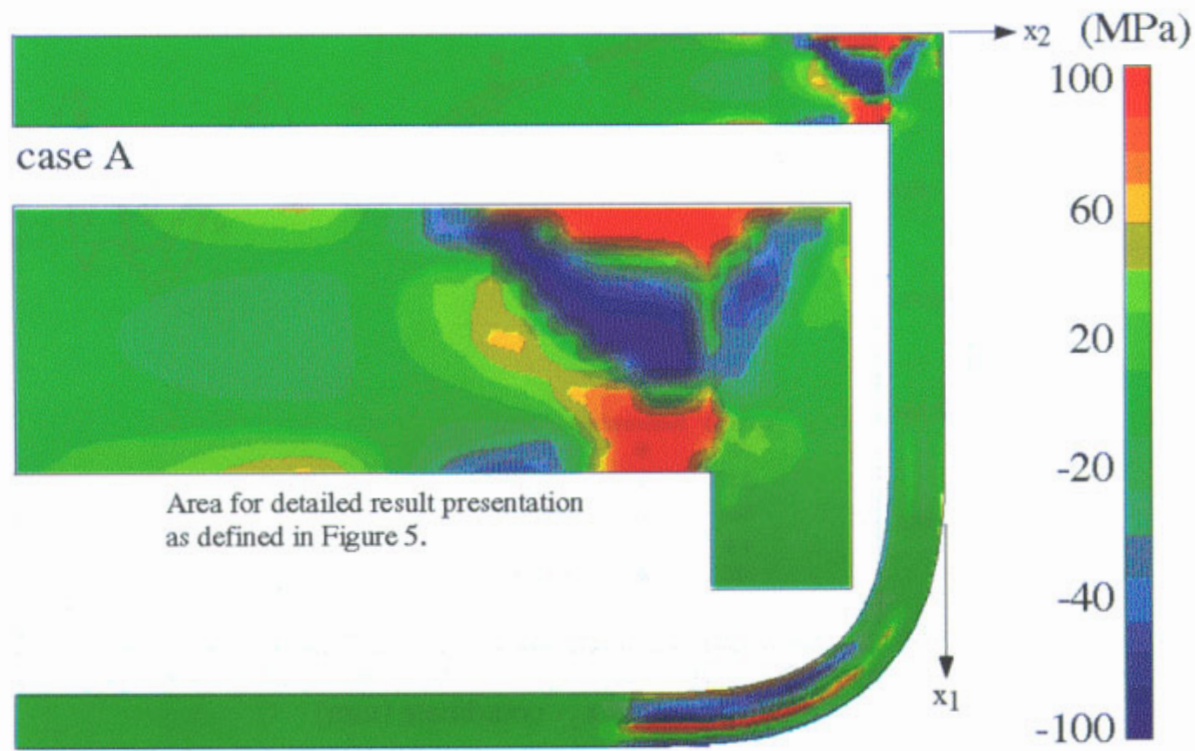

Mgure 14. Contours of calculated residtual $x_{2}$-strest, $\sigma_{22}$. Volume changes due to phase transformations are accounted for.

directions; the shrinkage of the filler material will cause high tensile stresses in the welded region and the material in the weld will yield plastically. These tensile stresses are balanced by compressive stresses elsewhere, particularly in the flat plate. In the U-shaped part the outof-plane stresses vary from compressive stresses on the inside of the bend to tensile stresses on the outside, due to the cold-bending operation. The main difference between the out of plane-normal residual stresses in case A and case B (figures 10(A) and (B) respectively) is that the tensile stress is substantially lowered in region of the weld in $10(\mathrm{~A})$, reflecting that this region has experienced solid-state phase transformation. Regarding the residual out-of-plane strain in case A and case B (figures 11(A) and (B)) the effect of solid-state phase transformation manifests itself in a similar way as with the stresses. In the area shown in figure 3, measured residual stresses and strains (figures 12 (A) and (B)) exhibit the expected behaviour, tensile stresses and positive strains in the welding region changing to compressive stresses and negative strains outside this area. The measured peak values for both $x_{3}$-strains and $x_{3}$-stresses are located in the filler material. Note the local maxima outside the welding groove in both strain and stress located approximately at $x_{1}=6 \mathrm{~mm}$, $x_{2}=-15 \mathrm{~mm}$.

Residual stresses in the $x_{1}$ - and $x_{2}$-directions (figures 13 and 14) resulting from the simulation where volume changes due to solid state transformation were accounted for (case A) are in a way similar to each other. The compressive stresses in the centre of the weld and the tensile stresses in the adjacent areas arise when the material in the weld centre expands due to solid-state transformations during cooling according to figure 7 , while the adjacent material does not expand. The material located at the area of the tensile residual stress peaks in figure 13 has not experienced any change in phase. This is not the case for the peaks in figure 14. Instead the peak-tensile stress areas have experienced that change of phase at an earlier stage.

Calculated normal strains in the area depicted in figure 3 for five difforent $x_{1}-c_{-}$ 

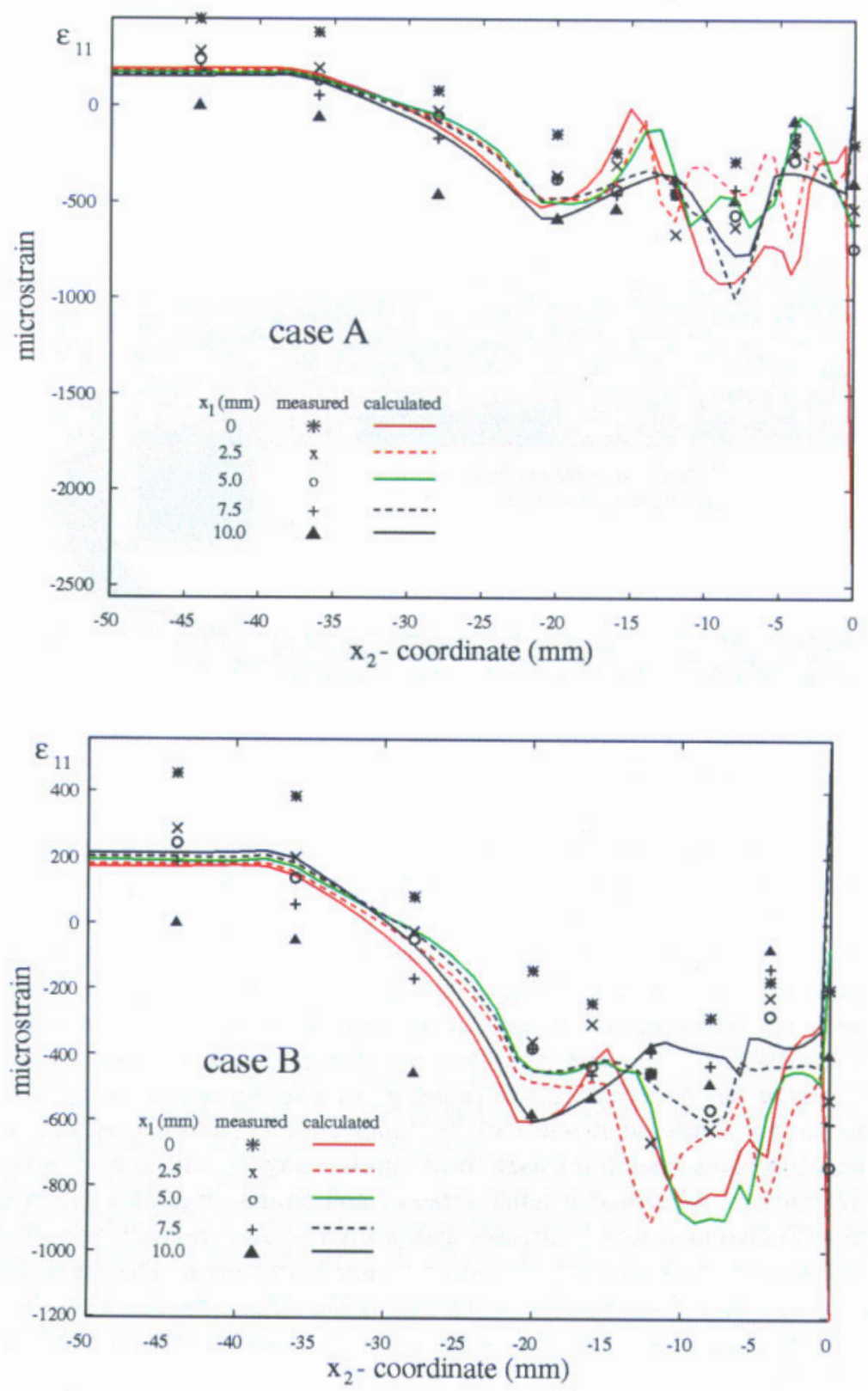

Figare 15. (A) Calculnted and meanum - 1 -strains, G11. Volume changes due to phase transformations are accounted for. (B) Calculated and mesured $x_{1}$-strains, 611 . Volume changes due to phase transformations are not accounted for.

ondinates, as well as the corresponding experimental values at nine different $x_{2}$-co-ordinates, are shown in figures 15-17. The average errors in the measured strains are as follows: $\delta \epsilon_{11}= \pm 43 \mu$ strain, $\delta \epsilon_{22}= \pm 51 \mu$ strain and $\delta \epsilon_{33}= \pm 97 \mu$ strain. In general for both analyses the overall behaviour outside the weld is reasonably modelled, even though the experimontal data display a greater through thickness $\left(x_{1}-\right)$ variation. As expected the 

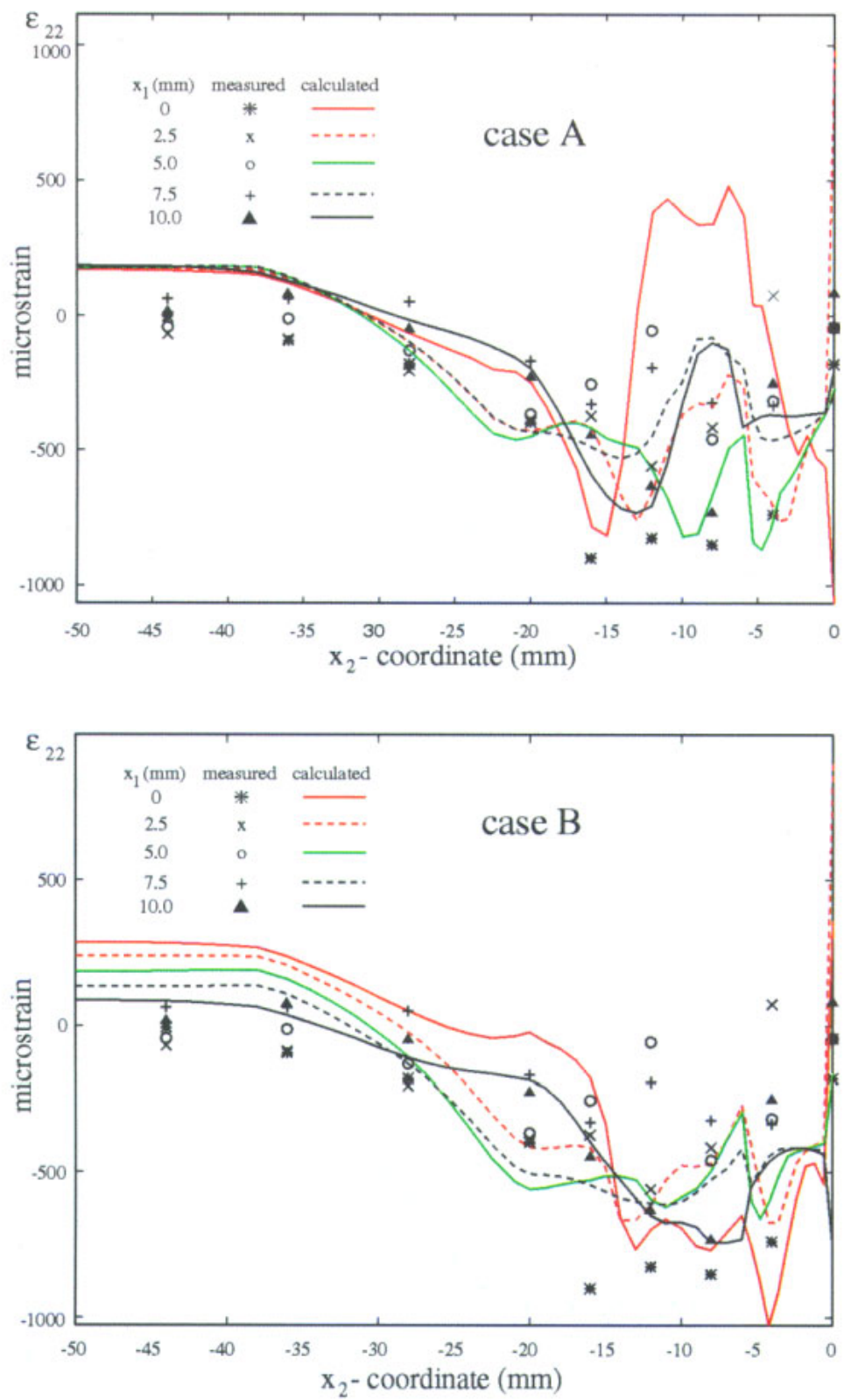

Figure 16. (A) Calcultad and measnred $x_{2}$-strains, 623. Volumo changes due to phase transformations ane accounted for. (B) Calculated and measured $x_{2}$-strains, $\epsilon_{22}$. Volume changes due to phase transformations are not accounted for.

calculated values in the welded region from the two different simulations deviate; this deviation is least pronounced in the $x_{1}$-direction (figure 15 ). This is probably due to the fact that the structure offers relatively little resistance to volume changes due to solid-state phase transformation in this direction. The results from the simpler model are closer to the experimentally detected values in this area. 

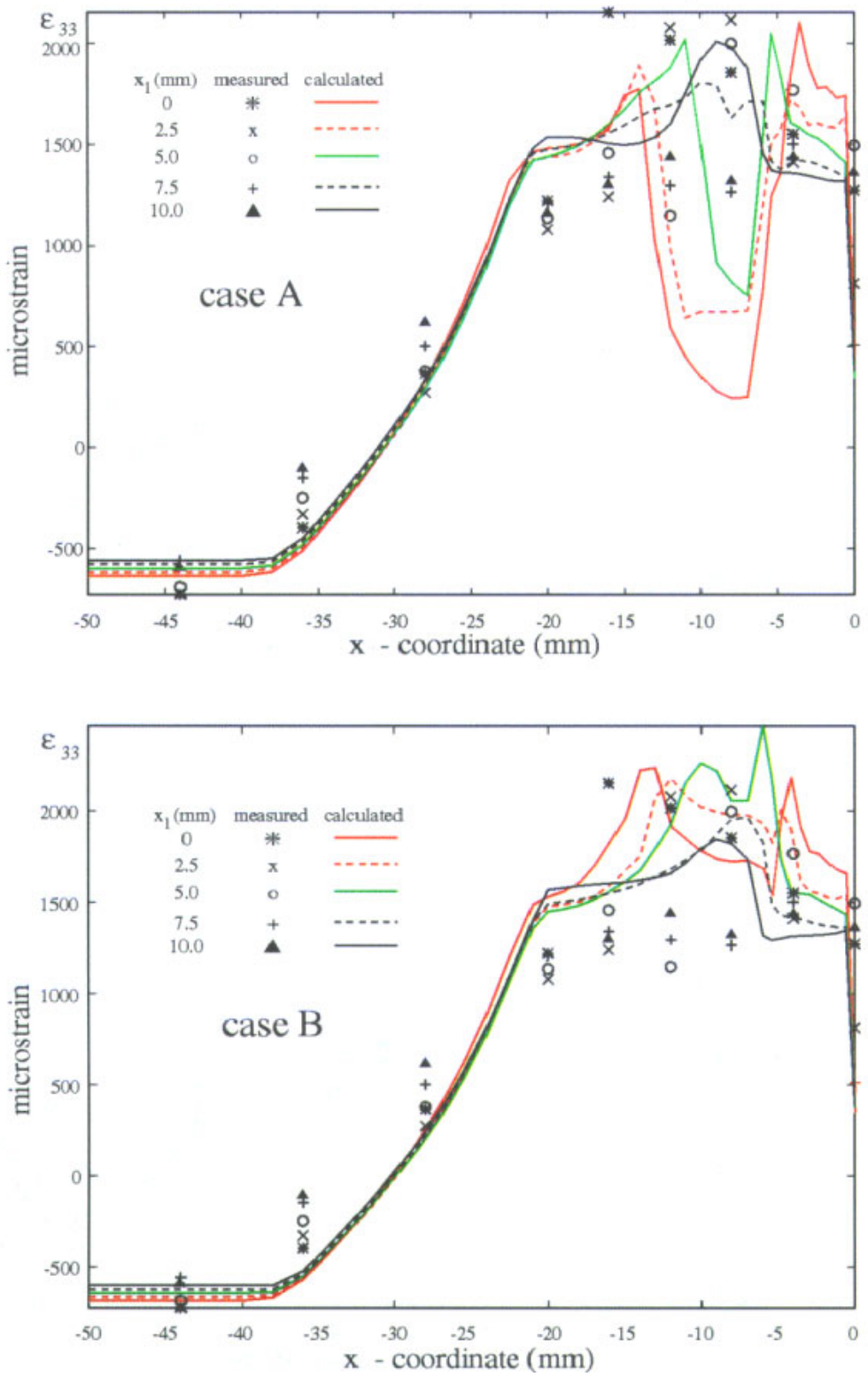

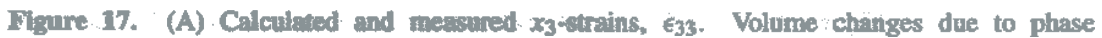
transformationis are accounted for. (B) Cillculated and measured $x_{3}+\$_{t r a i n s} \epsilon_{33}$. Volume changes due to phase transformations are not accounted for.

\section{Discussion and conclusions}

One can see from figures 15,16 and 17 that the overall prediction of the strains and stresses by the plane deformation model utilized here is reasonable, with the exception of the peak values in the weld metal. In the calculations the filler material is assumed to have the same material properties as the base metal SS 142132. A different set of material properties of 
the filler material would result in a change of the calculated stress and strain distributions, as well as the location and magnitude of the peak values, in the weld metal. The overall predicted residual bending deformation at the midpoint of the beam of length $2.45 \mathrm{~m}$ is $7 \mathrm{~mm}$. This value is very close to the beam midpoint pre-deformation adopted by the manufacturer. The total pre-deformation of the beam midpoint during manufacturing was $10-12 \mathrm{~mm}$, of which about $4 \mathrm{~mm}$ is due to elastic deformation.

The material modelling is of crucial importance. In the thermo-elastic-plastic material model adopted in this study the volume changes due to the solid-state phase transformations are accounted for by the thermal dilatation according to figure 7 . In the experiments performed (see [20]), in order to obtain the thermal dilatation in figure 7 no external mechanical loading was added, which means that the sample was free to move due to the temperature change and volume change from solid-state phase transformations. In the actual weld the material is constrained by the surrounding material and the solid-state phase transformations therefore occur under compressive load. This load influences the solid-state phase transformations in the way that additional plastic strains are formed. This phenomenon is referred to as transformation plasticity (see [21]). Transformation plasticity effects are not accounted for in this paper. A material model including transformation plasticity effects would give results for the residual strains in between case $A$ and case $B$. Volume changes due to solid-state phase transformation are accounted for in case A but not in case B. The residual longitudinal strain $\epsilon_{33}$ in the weld metal is considerably lower in case $A$ (see figure 11(A)) than in case $B$ (see figure $11(\mathrm{~B})$ ). The volume increase during cooling due to the solid-state phase transformations partially unloads the weld metal. This fact is reflected in figure $10(\mathrm{~A})$ (case $\mathrm{A}$ ) and figure $10(\mathrm{~B})$ (case $\mathrm{B}$ ).

In figure $17(\mathrm{~A})$ the dip in calculated longitudinal strain $\epsilon_{33}$ and corresponding stress $\sigma_{33}$ (figure 10(A)) in the weld metal can be explained by an overestimate of the volume increase due to phase transformations (figure 7). The thermal dilatation in the weld metal is assumed in the calculations to be the same as in the base metal SS 142132. The volume change due to phase transformations may be smaller in the weld metal than in the base metal. A smaller volume change due to phase transformations gives a smaller dip in calculated strain in the weld metal (figure 17(A)). Moreover, if effects of transformation plasticity are added, the dip in calculated strain $\epsilon_{33}$ in figure $17(\mathrm{~A})$ will decrease further. In case $B$ one can see from figure 17(B) that the dip in calculated residual strain $\epsilon_{33}$ in the weld metal does not appear. This behaviour is (as noted above) also shown in figure 11(B) for the residual strain $\epsilon_{33}$ and in figure 10(B) for the residual stress $\sigma_{33}$.

It can be concluded that the plane deformation model adopted in this study predicts overall bending of the beam satisfactorily. Also the overall prediction of residual strains and stresses is reasonable. Locally, in the weld metal the predicted residual strains and stresses will come close to the measured values, if a slightly smaller volume increase due to phase transformations for the weld metal than for the base metal is adopted. Inclusion of transformation plasticity effects will further enhance the calculated residual strains and stresses as compared to measured values.

\section{Appendix. Outline of the finite element procedure used in the welding analyses}

Box 1 gives the general time stepping procedure for the solution of a system of non-linear equations. The FE equations for the thermal analysis given in box 1 and box 2 follow the enthalpy method. The mechanical problem is solved in a time stepping procedure according to box 1 . The thermal and mechanical analyses are coupled via the thermal strain that enters 
the internal load $\boldsymbol{F}_{\text {int }}$ in box 3 . In the calculation of the stress increments a radial return method is used.

Box 1. The incremetal solution with iterative correction of a system of non-linear equations.

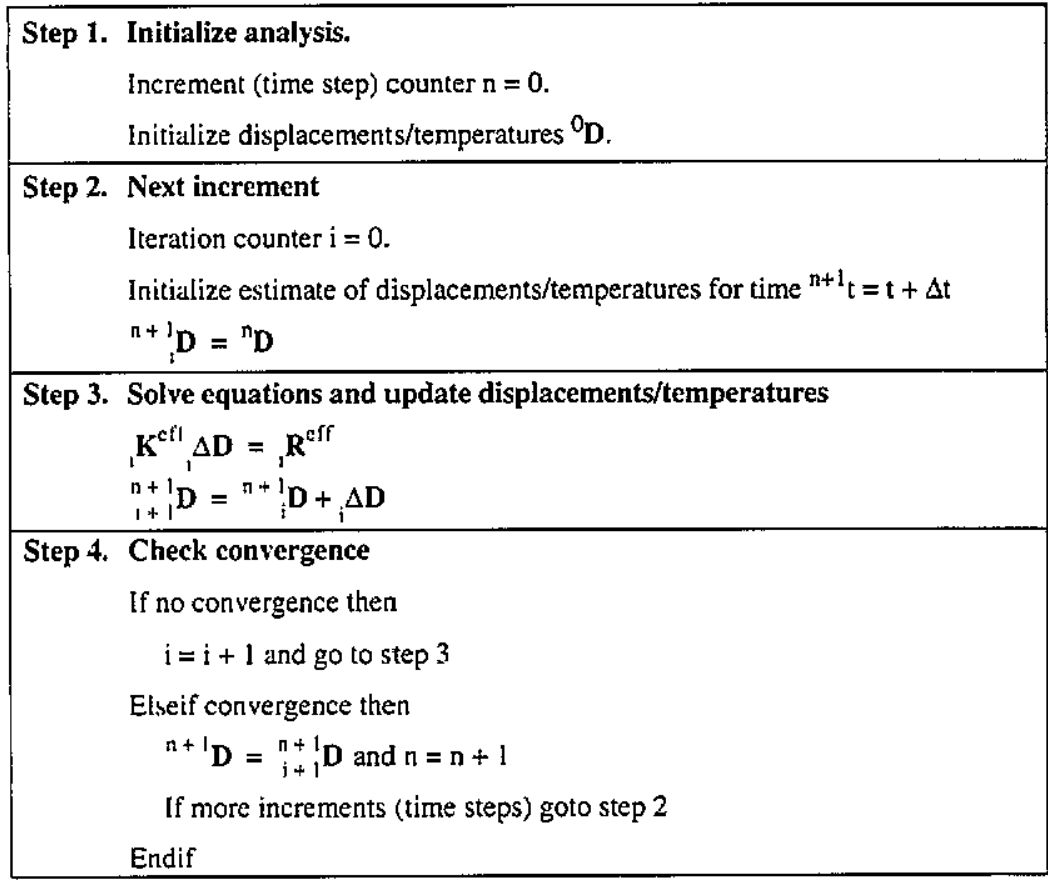

Box 2. The non-linear transient thermal analysis using the generalized midpoint rule for temporal integration.

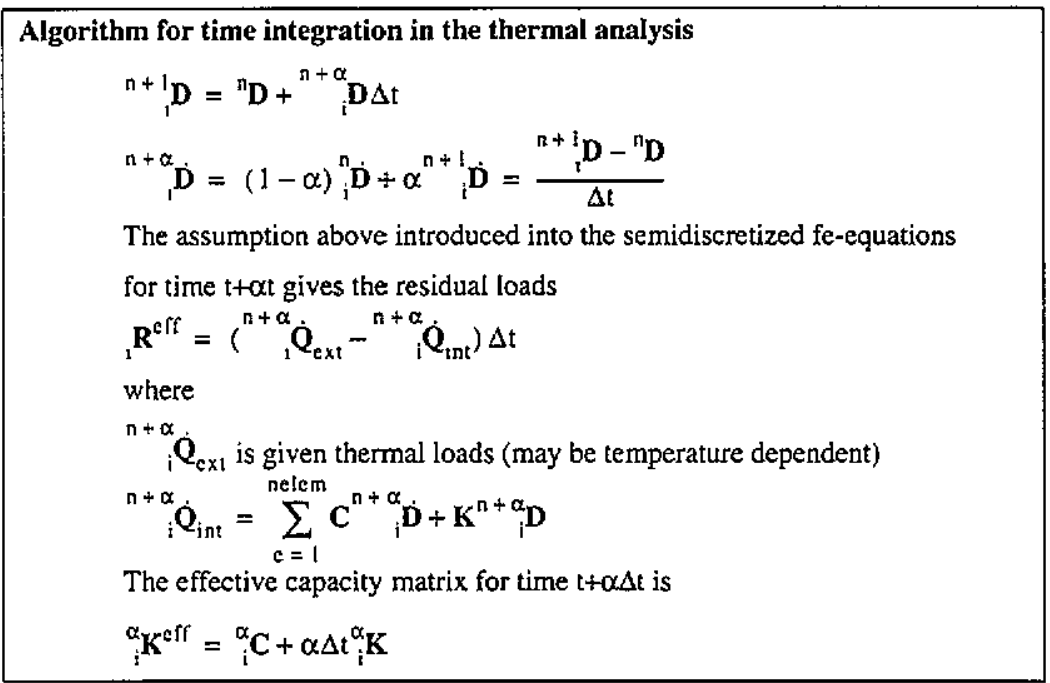


Box 3.

Nonlinear quasistatic mechanical analysis

$$
\begin{aligned}
& \mathbf{R}^{\mathrm{clf}}={ }^{n+1} \mathbf{F}_{\mathrm{cxt}}-{ }^{n+1} \mathbf{F}_{\text {in }} \\
& { }^{n+1} \mathbf{F}_{\mathrm{cxi}} \text { is given loads } \\
& { }_{\mathrm{I}}^{n+1} \mathbf{F}_{\mathrm{snt}}=\sum_{\mathrm{c}=1}^{\mathrm{nelem}} \int \mathbf{B}^{\mathrm{Tn}+1} \sigma d V^{\mathrm{e}}
\end{aligned}
$$

The effective stiffness matrix is the tangent stiffness matrix in the quasistatic case.

${ }_{1} \mathbf{K}^{\mathrm{eff}}={ }_{\mathbb{1}} \mathrm{K}$

\section{Notation}

$\dot{x}$ denotes a time derivative of $x$.

$\Delta x \quad$ denotes an incremental quantity of $x$.

${ }^{n} x$ denotes that the quantity is referred to at time ${ }^{n_{t}}$

$\mathrm{ix} \quad$ denotes the value of $\mathrm{x}$ at the $\mathrm{i}$ :th iteration

$\alpha \quad$ time integration factor for thermal analysis

D temperature or displacement $\quad\left[{ }^{\circ} \mathrm{C}\right]$ or $[\mathrm{m}]$

$\mathbf{K}^{\text {eff }} \quad$ effective capacity or stiffness matrix $\quad[\mathrm{J} / \% \mathrm{C}]$ or $[\mathrm{N} / \mathrm{m}]$

$\mathbf{R}^{\text {eff }} \quad$ effective thermal or mechanical loads $\quad$ [J] or [N]

$\dot{\mathbf{Q}}$ thermal loads [J/s]

C heat capacity matrix $\quad[\mathrm{J} / \mathrm{C}]$

K conductivity or stiffness matrix $\quad\left[\mathrm{J} /\left(\mathrm{s}^{\circ} \mathrm{C}\right)\right]$ or $[\mathrm{N} / \mathrm{m}]$

F mechanical loads [N]

B strain-displacement matrix [1/m]

$\sigma \quad$ stresses $\quad\left[\mathrm{N} / \mathrm{m}^{2}\right]$

\section{References}

[1] McDill M J, Goldak J A, Oddy A and Bibby M J 1987 Isoparametric quadrilaterals and hexahedrons for mesh grading elements Commun Appl. Numer. Methods 3 155-163

[2] Lindgren L-E and Karlsson L 1988 Deformations and stresses in welding of shell structures Int. J. Numer. Methods Eng. 25 635-55

[3] Näsström M, Wikander L, Karlsson L, Lindgren L E and Goldak J 1992 Combined 3D and shell modelling of welding Mechanical Effects of Welding ed L Karlsson, L E Lindgren and M Jonsson (Berlin: Springer) pp 197-206

[4] Brown S and Song H 1992 Implications of three-dimensional numerical simulations of welding of large structures Welding J. $7155-62$

[5] Wikander L, Näsström M and Karisson L 1993 Thermomechanical FE plane models of welding Modeling of Casting, Welding and Advanced Solidification Processes VI ed T S Piwonka, V Voller and L Katgerman (Warrendale, PA: The Minerals, Metals and Materials Society)

[6] Sachs G 1927 Der nachweis immerer spannungen instangen und rohren Z. Metall. 19 352-7 
[7] Ueda Y, Fukuda $\mathrm{K}$ and Tanigawa M 1979 New measuring method of three dimensional residual stresses based on theory of inherent strain Trans. JWRI 8 249-56.

[8] Mathar J 1934 Determination of initial stresses by measuring the deformation around drilled holes Trans. ASME 56 249-54.

[9] Beaney E M and Proctor E 1974 A critical evaluation of the centre hole technique for the measurement of residual stresses Strain $107-14$

[10] James M R and Buck O 1981 Quantitative non-destructive measurements of residual stresses CRC Critical Reviews in Solid State and Materials Science vol 9 (Boca Raton, FL: CRC Press) pp 61-105

[11] Langman R 1981 Measurement of the mechanical stress in mild steel by means of rotation of magnetic field strength $N D T$ Int. 14 255-62.

[12] James M and Cohen J B 1980 The measurement of residual stresses by x-ray diffraction techniques Exp. Methods Mater. Sci, Treatise on Mater. Sci. Technol. 19 A 1-62

[13] Allen A J, Hutchings M T and Windsor C G 1985 Neutron diffraction methods for the study of residual stress fields Adv. Phys. 34 445-73

[14] Stacey A, MacGillivray H J, Webster G A, Webster P J and Ziebeck K R A 1985 Measurement of residual stresses by neutron diffraction $J$. Strain Anal. 20 93-100.

[15] Hallqvist J O 1986 A vectorized implicit, finite deformation, finite element code for analysing the static and dynamic response of $2 \mathrm{D}$ solids with interactive rezoning and graphics University of California, Lawrence Livermore National Laboratory, Report UCID-19677

[16] Karlsson L and Lindgren L E 1991 Combined heat and stress-strain calculations Modelling of Casting, Welding and Advanced Solidification Processes V ed M Rappaz, M R Ozgu and K W Mahin (Warrendale, PA: The Minerals, Metals and Materials Society)

[17] Andersson B A B 1978 Thermal stresses in a submerged-are welded joint considering phase transformations ASME J. Eng. Mater. Technol. 100 356-62

[18] Jonsson M, Karisson L and Lindgren L E 1985 Deformations and stresses in butt- welding of large plates Numerical Methods in Heat Transfer vol III, ed R W Lewis and K Morgan (London: Wiley)

[19] Jonsson M, Karlsson L and Lindgren L E 1985 Deformations and stresses in butt-welding of large plates with special reference to the mechanical material properties ASME J. Eng. Mater. Technol. 107 265-70

[20] Troive L, Karlsson L, Näsström M and Low K S 1989 Finite element simulations of the bending of a flat plate to U-shaped beam cross-section and neutron diffraction determination of residual stresses Recent Trends in Welding Science TWR'89 ed S A David and J M Vitek (Materials Park, OH: ASM International) pp 107-11

[21] Oddy A S, Goidak J A and McDill J M J 1989 Transformation effects in the 3D finite element analysis of welds Recent Trends in Welding Science TWR'89 ed S A David and J M Vitek (Materials Park, OH: ASM International) pp 97-101 